\title{
É POSSÍVEL ENSINAR LEITURA? METAINFERÊNCIA, UM CAMINHO PARA A LEITURA EM SALA DE AULA
}

\section{IS IT POSSIBLE TO TEACH READING? METAINFERENCE, A WAY FOR READING IN THE CLASSROOM}

\section{DOI 10.20873/uft2179-3948.2021v12n2p361-381}

\author{
Flávia Azambuja ${ }^{1}$ \\ Diego Vargas ${ }^{2}$ \\ Taíse Simioni ${ }^{3}$ \\ Clara Dornelles ${ }^{4}$
}

\begin{abstract}
Resumo: O objetivo deste artigo é investigar a contribuição da metainferência ao ensino de leitura, a partir da análise de práticas que levam em conta cognitiva e metacognitivamente os processos inferenciais de leitura. Metodologicamente, analisamos dados de uma pesquisa-ação, da qual participaram alunos do Ensino Médio de uma escola pública de Bagé/RS. Houve resultados positivos relacionados a: (i) valorização de conhecimentos prévios, (ii) estabelecimento de objetivos e hipóteses e (iii) desenvolvimento de estratégias para avaliação e monitoramento da compreensão. Assim, este trabalho permite afirmar que o ensino de leitura é possível e um dos caminhos é o trabalho com a metainferência.
\end{abstract}

Palavras-chave: metainferência; leitura integrativa; ensino de leitura; pesquisa-ação.

Abstract: The objective of this article is to investigate the contribution of meta-inference to reading teaching, based on the analysis of practices that take cognitive and metacognitive account of inferential reading processes. Methodologically, we analyzed data generated in an action research, in which high school students from a public school in Bagé/RS participated. There were positive results in relation to the: (i) valorization of previous knowledge, (ii) establishment of objectives and hypotheses and (iii) development of explicit strategies for

\footnotetext{
1 Mestre em Ensino de Línguas e graduada em Letras pela Unipampa. Professora de Língua Portuguesa na Prefeitura Municipal de Bagé e de Português como Língua Adicional no programa Centro de Línguas do Pampa. E-mail: flaviaalves.aluno@unipampa.edu.br ORCID: https://orcid.org/0000-0001-8674-5342

2 Doutor em Letras Neolatinas pela Universidade Federal do Rio de Janeiro; Mestre em Letras Vernáculas, Bacharel e Licenciado em Letras, também pela UFRJ. Professor Adjunto do Departamento de Didática da Universidade Federal do Estado do Rio de Janeiro (UNIRIO) e Professor do Programa Interdisciplinar de Pósgraduação em Linguística Aplicada da UFRJ. Atualmente, compõe a Comissão de Linguística Aplicada da ABRALIN)e o GT Ensino e Aprendizagem na Perspectiva da Linguística Aplicada da ANPOLL. E-mail: dsvargas04@yahoo.com.br ORCID: https://orcid.org/0000-0001-6292-256X.

${ }^{3}$ Graduada, mestre e doutora em Letras pela Universidade Federal do Rio Grande do Sul. Professora Associadana Universidade Federal do Pampa. E-mail: taisesimione@unipampa.edu.br ORCID: https://orcid.org/0000-00029778-7393.

${ }^{4}$ Graduada e mestre em Letras pela UFSC; doutora em Linguística Aplicada pela UNICAMP. Atualmente é docente no curso de Letras Línguas Adicionais - Inglês/Espanhol e Respectivas Literaturas e atua no Programa de Pós-graduação em Ensino de Línguas/Mestrado Profissional da UNIPAMPA. E-mail: claradornelles@unipampa.edu.br ORCID: https://orcid.org/0000-0001-6472-7354.
} 
evaluation and monitoring of understanding. Thus, this work allows to affirm that the teaching of reading is possible and one of the ways for this is the work with the metainference.

Keywords: metainference; integrative reading; reading teaching; action research.

\section{Introdução}

O ensino de leitura na escola, apesar das pesquisas feitas sobre o assunto na esfera acadêmica, parece não ter avançado muito (KLEIMAN; MORAES, 1999; KLEIMAN, 2001; ROJO, 2003; BATISTA; COSTA VAL, 2004; LAJOLO, 2008; BATISTA, 2009; ROJO; MOURA, 2012). Lajolo (2008) e Gabriel et al. (2016) ressaltam a tensão existente entre livros didáticos, políticas públicas e escola e criticam a forma como a leitura é tratada no âmbito escolar, quando são ignoradas as ações realizadas por um leitor proficiente e há um direcionamento de interpretações.

Tal reflexão é importante porque, apesar de o professor poder optar por não usar um material dado ou por usá-lo mais autoralmente, muitas vezes, pela precariedade de suas condições de trabalho, o segue como um guia (BATISTA, 2003; BATISTA, 2004). Nesse sentido, Marcuschi (2003) revela que, em livros didáticos, compreender um texto passa a ser extrair informações. Além disso, as questões de compreensão aparecem misturadas com outras não pertinentes ao tema, ou que nem precisam da leitura do texto ou que não exigem posicionamento crítico dos alunos.

Então, como mudar o tratamento dado à compreensão leitora na escola? Gabriel et al. (2016) sugerem que se proponham práticas de ensino de leitura, desde a etapa de alfabetização, fundamentadas nas especificidades do processo de aprendizagem da leitura e no processamento da leitura desenvolvido pelo leitor proficiente, e amparadas em conhecimentos advindos da ciência da leitura. Neste artigo, partindo desta perspectiva, buscamos contribuir para o desenvolvimento dessas práticas, ao propormos uma didática da metainferência em leitura baseada em trabalhos que se dedicam a compreender como ocorrem cognitiva e metacognitivamente os processos inferenciais realizados pelo leitor proficiente.

Entendemos que o caminho está no trabalho escolar com as chamadas estratégias metacognitivas de leitura. Dentro desta perspectiva, não mais se pretende apontar leituras corretas ou erradas ou conduzir os estudantes à construção de uma mesma leitura de um texto, mas sim auxiliá-los na sua própria construção como sujeitos leitores, capazes de pensar sobre seus próprios processos leitores a partir de objetivos específicos (estabelecidos por si mesmos ou por determinadas situações sociais de leitura). 
Segundo Botelho e Neves (2019, p.191), “é possível atuar metacognitivamente por meio da proposta de questões orientadas sob objetivos e hipóteses flexíveis que auxiliem na compreensão e na construção de significados a partir da experiência com o texto". Nesse sentido, cabe ressaltar que, ainda que desde os anos 80, publicações sobre o ensino de leitura no Brasil apontem para a necessidade do trabalho com a leitura em nível metacognitivo, diversos trabalhos demonstram o fato de que isso não se concretiza, ainda hoje, nas práticas escolares (cf. BOTELHO e NEVES, 2019).

Em um desses trabalhos clássicos, Kleiman (2009) diz que é papel da escola trabalhar, na leitura, com as estratégias metacognitivas. Entretanto, ao propor este trabalho, que inaugura uma perspectiva de leitura no Brasil, a autora acaba por não diferenciar habilidades de estratégias, o que dificulta a concretização de tal perspectiva em sala de aula. Duffy e Roehler (1989) indicam que essa diferenciação é essencial para a construção de propostas pedagógicas efetivas baseadas no que fazem os chamados leitores experientes.

Para os autores, enquanto as habilidades estão associadas a procedimentos rotineiros, sendo utilizadas de forma automatizada, as estratégias se constroem como planos flexíveis adaptados às demandas de compreensão do texto, não podendo, portanto, ser procedimentalizadas. Eles indicam ainda que, entre outras coisas, o trabalho com as estratégias deve ser longitudinal, de forma que o estudante possa compor um repertório de estratégias, exige a explicitação constante por parte dos professores e o desenvolvimento de um controle metacognitivo por parte dos estudantes, apoiado nos processos apresentados pelos docentes. Essa diferenciação se torna ainda hoje relevante quando vemos que propostas curriculares que buscam conduzir o trabalho dos professores em aula estão ainda pautadas na ideia de competências e habilidades, ignorando o papel central das estratégias ou mesmo confundindo os conceitos ao citá-las.

Neste trabalho, analisamos uma tarefa de leitura de uma intervenção pedagógica focada no trabalho com as chamadas estratégias de leitura, realizada com uma turma de terceiro ano do Ensino Médio de uma escola pública em Bagé (RS). ${ }^{5} \mathrm{O}$ enfoque desta intervenção está na chamada metainferência, uma vez que, para Kleiman (2009), entre outros autores, o que fica da leitura são as inferências que fazemos. Por isso, levar os alunos a construírem conhecimentos sobre as inferências e refletirem sobre seu processo inferencial pode trazer ganhos ao ensino de leitura. A análise de um recorte da intervenção, que teve a duração total de três meses, permitiu

\footnotetext{
${ }^{5}$ Cabe destacar aqui que este trabalho parte de dados gerados na realização da pesquisa que deu origem à dissertação da Azambuja (2018), defendida no Mestrado em Ensino de Línguas da Universidade Federal do Pampa - Unipampa. Entretanto, a discussão realizada ao longo deste artigo amplia a análise desenvolvida na dissertação.
} 
observar como a discussão explícita envolvendo estratégias metacognitivas sobre a construção de inferências pode contribuir para o ensino de leitura.

Na sequência, discorremos sobre os pressupostos que fundamentaram o planejamento, a implementação e a análise da intervenção a partir da qual foram gerados os dados discutidos neste trabalho. Além disso, explicitamos os procedimentos metodológicos adotados para a seleção e a análise do recorte feito neste trabalho e propomos novas discussões dos dados gerados a partir deste recorte.

\section{Pressupostos teóricos}

Na seção 2.1, discutimos os conceitos de inferência e de leitura que orientam este trabalho, a partir do conceito de integração conceptual. A seção 2.2 se dedica a apresentar uma discussão sobre o processo de ensino-aprendizagem da leitura que leve em consideração as estratégias metacognitivas.

\subsection{O que fica da leitura?}

Como dito anteriormente, diversos estudos já demonstraram que o que fica de uma leitura são as inferências construídas pelo leitor e não a retenção de informações explicitamente apresentadas no texto. Para Vargas (2012), a inferenciação

\footnotetext{
é um processo de formação de conceitos (inferências) que se dá a partir da integração conceptual entre dois inputs de informação: o conhecimento prévio do leitor e a informação visual apresentada pelo texto. A inferência, por sua vez, possui um caráter imprevisto e particular, sendo um elemento novo relativamente aos inputs. (Vargas, 2012, p. 85)
}

O input 1 diz respeito ao conhecimento prévio do leitor, selecionado a partir de determinados frames ativados pelo texto (DUQUE, 2015); o input 2 está ligado à seleção de informações presentes no texto (o que também acontece a partir dos frames). No espaço mescla, se forma algo novo em relação aos inputs, com a mediação do espaço genérico, onde se encontra o que há de comum entre os dois inputs (VARGAS, 2015).

A inferência acontece no processo de construção do espaço mescla, na relação entre os dois inputs - conhecimento prévio e informações selecionadas do texto. Há na mescla mais do que elementos em comum aos dois inputs, já que informações podem ir direto de um dos inputs para este espaço. Além disso, informações que dependem dos dois inputs, mas que não estão neles, podem aparecer. A essas novas informações, construídas por conta do processo de integração conceptual (como se vê na Fig. 1) denominamos inferência. 
Figura 1. Mapa de integração conceptual

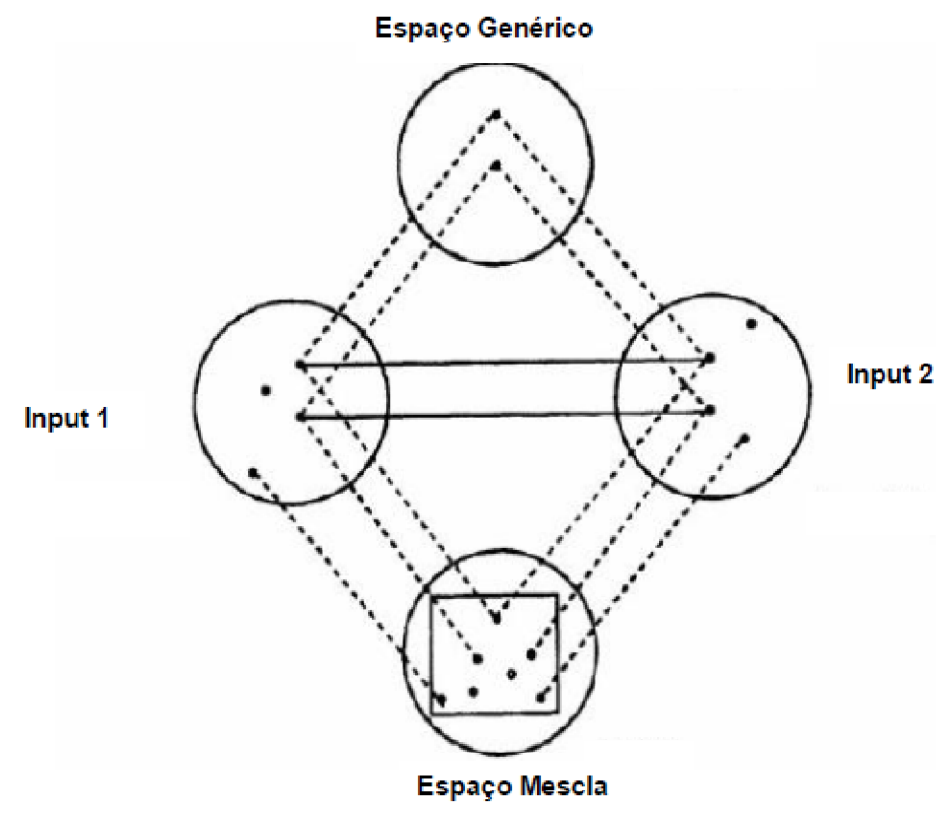

Fonte: adaptação de Fauconnier e Turner (2002, p. 9)

Dentro do input 1, há pequenos círculos preenchidos que representam o conhecimento prévio ativado; no input 2 , há círculos preenchidos representando a seleção das informações do texto. As linhas contínuas representam a relação construída pelo leitor entre os inputs e as linhas tracejadas indicam a projeção desses aspectos no espaço genérico. Essas relações são também projetadas no espaço mescla, representado por um quadrado, que inclui as informações dos inputs ligadas a eles por linhas tracejadas e informações novas que, apesar de não estarem nos inputs, só são possíveis a partir deles. Essas informações são representadas pelos círculos vazios (GERHARDT, 2010; VARGAS, 2015).

Como os inputs são individuais, as inferências também serão, sendo a inferenciação um processo de negociação de sentidos. O leitor não pode inferir qualquer coisa, mas também não pode ser impedido de fazer inferências que vão além das expectativas do produtor do texto (VARGAS, 2015). O conceito de inferenciação tem relação com a leitura integrativa, concepção de leitura adotada neste trabalho e que entende texto como ponte entre autor e leitor. Os sentidos são construídos na integração conceptual entre conhecimento prévio e a informação selecionada do texto.

\subsection{Como trabalhar com o ensino de leitura?}

Ainda que os processos anteriormente apresentados sejam aqueles realizados pelos leitores, em diferentes níveis a partir de suas experiências de leitura, a escola parece ignorá-los, 
solicitando leituras que exigem essencialmente a reprodução dos textos lidos (cf. BOTELHO e NEVES, 2019). Como apontam Gabriel et al. (2016, p. 932), "se, para os leitores proficientes, ler parece ser uma habilidade tão natural quanto falar, esse não é o caso do leitor aprendiz ou daquele que não aprendeu a ler". Por isso, para os autores, dentro de uma perspectiva que concilia alfabetização e letramento, é importante que a interferência e a ação pedagógica se deem no processo que leva o leitor a se construir como uma pessoa alfabetizada.

Conforme apontam Duffy e Roehler (1989), quanto menor for o nível de letramento dos estudantes, maior será a necessidade de se trabalhar explicitamente com as estratégias de leitura em sala de aula. Dessa maneira, as estratégias podem ir se convertendo em habilidades automatizadas aplicadas em práticas sociais de leitura. Nesse sentido, não podemos nos esquecer que, segundo Gerhardt (2010), o aprendizado é um processo de formação de conceitos que se dá por meio da integração conceptual entre as experiências de quem aprende e os saberes novos a serem aprendidos, no qual acontece uma seleção do que já sabemos e do que devemos aprender, criando algo novo a partir desses inputs.

$\mathrm{Na}$ escola, o aluno precisa relacionar duas realidades para que a aprendizagem se dê: a sua realidade e a da escola (GERHARDT, 2010). Assim, entendemos que o aprendizado é um processo que estabelece relação com a construção de inferências e com a leitura integrativa, o que implica, então, discutir o ensino, já que são processos interligados.

Kleiman (2001), ao inaugurar a perspectiva aqui apresentada no Brasil, apontou para a possibilidade de se ensinar leitura por meio do trabalho com estratégias cognitivas e metacognitivas. Para a autora, seriam estratégias cognitivas o que Duffy e Roehler (1989) chamam de habilidades automatizadas, sobre as quais o leitor não consegue verbalizar, cabendo ao professor ajudar a desenvolvê-las. Um exemplo de estratégia cognitiva é a transformação de sinais escritos em linguagem - a decodificação, o que é parte do processo de construção de sentidos. O leitor não vai conseguir falar sobre as palavras que reconhece imediatamente, mas o professor pode colaborar, por exemplo, criando condições para a ampliação do vocabulário e para a reflexão sobre as possibilidades de sentidos associadas às palavras (KLEIMAN, 2001; GABRIEL et al., 2016).

Já as estratégias metacognitivas, essas sim, seriam desenvolvidas de modo ativo e consciente, levando os leitores a avaliarem e monitorarem sua leitura, além de (re)elaborarem caminhos para serem mais proficientes e autônomos, o que favorece a compreensão (KLEIMAN, 2001; CAVALCANTE, 2015). Nesse sentido, Gabriel et al. (2016) ressaltam a necessidade de um trabalho escolar que não considere a simples exposição à leitura e às práticas 
de letramento como estratégia para que a pessoa "naturalmente" aprenda a ler. Botelho e Neves (2019, p.191) acrescentam que:

\begin{abstract}
o monitoramento e o controle são processos distintos que atuam articuladamente na construção de duas dimensões para a metacognição em atividades de leitura: (a) por um lado, o monitoramento pode corresponder, por exemplo, tanto às ações de autoavaliação que o aluno pode desenvolver por meio de previsões sobre seu desempenho na atividade de leitura ou de escrita, quanto às ações de julgamento sobre a própria atividade a ser realizada, a partir da formulação de hipóteses sobre um texto a ser lido; e (b) por outro lado, o controle da ação cognitiva pode corresponder às ações de gerenciamento propostas para que o aluno realize sua leitura, por exemplo, em função de um resultado desejado, a partir da postulação de objetivos e de estratégias para seleção de informações, da orientação das tarefas a serem realizadas e, possivelmente, da resolução deproblemas.
\end{abstract}

Para Kleiman (2001) e para Duffy e Roehler (1989), o professor tem papel central na ampliação das estratégias metacognitivas dos alunos: é papel do professor, por exemplo, estabelecer objetivos de leitura para que depois os estudantes consigam fazê-lo, ou ainda, verificar se uma leitura se dá no nível da decodificação. Os autores também discutem a importância de os professores elaborarem atividades que ativem o conhecimento prévio dos alunos, servirem de modelo de leitor estratégico para os alunos e atuarem de maneira responsiva ao que dizem seus estudantes em relação a seus próprios processos.

Gerhardt et al. (2015) também destacam a importância do trabalho do professor no desenvolvimento e manutenção dos objetivos e na formulação de hipóteses de leitura a partir de conhecimentos prévios para que os leitores desenvolvam confiança e passem a solucionar problemas encontrados durante sua leitura. Igualmente, Vargas (2017) aponta para a importância da orientação do professor, que deve ajudar o aluno até que ele consiga desenvolver uma leitura eficiente. Para isso, é preciso que as tarefas de orientação sejam constantes; uma tarefa isolada não resolve os problemas de leitura que os alunos podem ter.

Para Díaz (2003), as estratégias metacognitivas envolvem o leitor ter consciência de sua compreensão, do que ainda precisa compreender, e ainda ter consciência sobre a importância das estratégias metacognitivas na solução de problemas. Para a autora, a ideia de que se aprende a ler apenas lendo é equivocada; o professor tem um papel fundamental de ensinar estratégias que levem os alunos a ter mais consciência de seu processo inferencial, e, assim, aprendam a ler lendo, mas também refletindo sobre a leitura. Além disso, para Díaz (2003), os professores devem falar sobre seu próprio processo inferencial. A autora ressalta que os reflexos da falta de ensino de leitura são alunos que afirmam não compreender nada, mas conseguem responder a perguntas inferenciais sobre o texto, e alunos que afirmam compreender tudo, mas não conseguem respondê-las. 
Segundo Díaz (2003), a metainferência diz respeito ao leitor ter controle metacognitivo sobre seu processo inferencial. Também diz respeito a ter conhecimentos sobre inferências. É importante fazer uma ressalva: o conceito de inferência proposto pela autora não é o mesmo com que trabalhamos. Para Díaz, inferência é estabelecer relação entre o texto, o contexto e o conhecimento prévio. Para nós, vai além disso, visto que inferenciar é criar algo diferente do que há no texto e do que havia de conhecimento prévio. É a partir desta perspectiva que compreendemos o conceito de metainferência. Essa reflexão sobre o processo inferencial é o que a intervenção, a partir da qual foram gerados os dados discutidos neste trabalho, se propôs a intermediar para tornar os alunos mais proficientes e críticos.

A próxima seção descreve a metodologia adotada nesta pesquisa.

\section{Metodologia}

Os dados analisados neste artigo foram gerados em uma pesquisa-ação. Para Tripp (2005), pesquisa-ação é uma tentativa de melhorar a prática de ensino, embasada teoricamente e de maneira contínua. É importante salientar que é também uma maneira de compreender a prática e, assim, poder fazer generalizações. Primeiro, identificamos um problema: aqui, a leitura no nível da decodificação realizada pela maioria dos alunos. Em seguida, pensamos uma possível solução para o problema, intervimos e revemos a intervenção para avaliar em que medida os objetivos foram atingidos. Além disso, a pesquisa-ação envolve revisão de planejamento durante toda a intervenção. Nesta pesquisa, partimos do pressuposto de que uma possibilidade para alcançar uma leitura proficiente e crítica seja a explicitação de inferências.

A intervenção, planejada em torno de tarefas que formam uma WebQuest com o tema da representação da mulher, ocorreu entre maio e setembro de 2018 e foi conduzida por Azambuja, que atuou, neste contexto, como professora-pesquisadora. O Quadro 1 apresenta uma síntese das tarefas que constituem a intervenção.

Quadro 1. Tarefas da WebQuest "Músicas para (re)pensar o papel da mulher em nossa sociedade"

\begin{tabular}{|c|c|}
\hline Tarefas/Textos utilizados & Objetivos \\
\hline $\begin{array}{c}\text { Tarefa 1: "Cultura, preconceito, agonia, casa, } \\
\text { racismo, feminismo e identidade" } \\
\text { (https://www.facebook.com/transleituras/) }\end{array}$ & $\begin{array}{c}\text { Refletir sobre as produções e o } \\
\text { planejamento de uma exposição. }\end{array}$ \\
\hline $\begin{array}{c}\text { Tarefa 2: "Giz, lousa e livro didático não cumprem o o } \\
\text { papel de representar o contexto vivenciado pelos } \\
\text { alunos" (vídeo utilizado não está mais disponível). }\end{array}$ & $\begin{array}{c}\text { Analisar e aprimorar um verbete sobre } \\
\text { multimodalidade. }\end{array}$ \\
\hline $\begin{array}{c}\text { Tarefa 3: "Eu hein... Nem morta" } \\
\text { (https://www.pensador.com/frase/MTM3OTAy/) }\end{array}$ & $\begin{array}{c}\text { Refletir sobre inferências e a } \\
\text { importância do conhecimento prévio. }\end{array}$ \\
\hline
\end{tabular}




\begin{tabular}{|c|c|}
\hline $\begin{array}{c}\text { Tarefa 4: "O inédito e o único de cada leitura" } \\
\text { (http://iunipampa.info/educacao/o-inedito-e-unico- } \\
\text { de-cada-leitura/) }\end{array}$ & $\begin{array}{l}\text { Perceber diferentes conceitos de } \\
\text { inferência. }\end{array}$ \\
\hline $\begin{array}{l}\text { Tarefa 5: "O que quer uma mulher" } \\
\text { (encurtador.com.br/knM06) }\end{array}$ & $\begin{array}{l}\text { Perceber marcas de representação de } \\
\text { homem e de mulher. }\end{array}$ \\
\hline $\begin{array}{l}\text { Tarefa 6: "Representações de mulher" } \\
\text { (https://pixabay.com/pt/vectors/modelos-de-moda- } \\
\underline{\text { modelos-moda-154934/) }}\end{array}$ & $\begin{array}{l}\text { Analisar as representações de mulher } \\
\text { em um texto imagético. }\end{array}$ \\
\hline $\begin{array}{l}\text { Tarefa 7: "Música escrota que ninguém problematiza } \\
\text { porque não é funk" } \\
\text { (http://www.virgula.com.br/album/;musica-uma- } \\
\frac{\text { construcao-de-genero-exposicao-da-prefeitura-de- }}{\text { sao-leopoldo/\#img=5\&galleryld }=1272604 \text { ) }}\end{array}$ & $\begin{array}{l}\text { Estabelecer relações entre post e } \\
\text { campanha. }\end{array}$ \\
\hline $\begin{array}{c}\text { Tarefa 8: "Mamacita fala, vagabundo senta" } \\
\text { (https://www.youtube.com/watch?v=LfL4H0e5-Js) }\end{array}$ & Perceber a representação de mulher. \\
\hline $\begin{array}{c}\text { Tarefa 9: "Amélia que era mulher de verdade" } \\
\text { (https://www.youtube.com/watch?v=KnHbjv7TRQY) }\end{array}$ & $\begin{array}{c}\text { Analisar representações de homem e } \\
\text { mulher. }\end{array}$ \\
\hline $\begin{array}{l}\text { Tarefa 10: "Eu to falando do axé politicamente } \\
\text { correto" (https://globoplay.globo.com/v/5487692/) }\end{array}$ & $\begin{array}{l}\text { Refletir sobre as representações de } \\
\text { mulher na música original e na } \\
\text { paródia. }\end{array}$ \\
\hline $\begin{array}{l}\text { Tarefa 11: "E eis que de repente, ela resolve então } \\
\text { mudar" } \\
\text { (https://www.youtube.com/watch?v=ygcrcRgVxMl) }\end{array}$ & $\begin{array}{l}\text { Estabelecer relações entre duas } \\
\text { músicas. }\end{array}$ \\
\hline $\begin{array}{c}\text { Tarefa 12: “'hai’ (brincadeira, gracejo) e ‘kai’ } \\
\text { (harmonia, realização)" } \\
\text { (https://www.todamateria.com.br/o-que-e-haicai/) }\end{array}$ & Apropriar-se do gênero haicai. \\
\hline $\begin{array}{l}\text { Tarefa 13: "No cinzeiro um cigarro, manchado de } \\
\text { batom" } \\
\begin{array}{l}\text { (http://www.sumauma.net/gremio/palestra- } \\
\text { rosa.html) }\end{array}\end{array}$ & $\begin{array}{c}\text { Refletir sobre a representação de } \\
\text { mulher. }\end{array}$ \\
\hline $\begin{array}{l}\text { Tarefa 14: "A pia tá cheia de louça/ O banheiro parece } \\
\text { que é de botequim/ A roupa toda amarrotada/ E você } \\
\text { nem parece que gosta de mim" } \\
\text { (https://www.youtube.com/watch?v=lTeb3xT0pG4) }\end{array}$ & $\begin{array}{l}\text { Refletir sobre as diferenças entre } \\
\text { representações de homem e de } \\
\text { mulher. }\end{array}$ \\
\hline
\end{tabular}

Fonte: Elaboração própria.

Participou da intervenção uma turma de terceiro ano do Ensino Médio de uma escola pública estadual de Bagé (RS). Os alunos maiores de 18 anos ou os responsáveis, no caso dos alunos menores de 18 anos, assinaram um termo de consentimento.

Essa escola está localizada em uma zona central e tem pouco mais de 500 alunos. Lendo os dados do Sistema de Avaliação do Rendimento Escolar do Rio Grande do Sul (SAERS) de 2016, nos chamou atenção os resultados do Ensino Médio relativos à leitura, abaixo da média do estado, evidenciando a importância desta pesquisa. O planejamento da intervenção envolveu pensar uma proposta de trabalho com a metainferência.

Os dados foram gerados durante a intervenção por meio de gravação, em áudio, das aulas e de uma roda de conversa que ocorreu no último encontro. A análise se deu de forma 
qualitativa, com base nas categorias: (i) mobilização do conhecimento prévio, (ii) estabelecimento de objetivos e hipóteses de leitura e (iii) avaliação e monitoramento da compreensão. Tais categorias levam em consideração diferentes processos envolvidos na construção da leitura inferencial e na reflexão sobre seu desenvolvimento. As gravações da intervenção permitiram retomar acontecimentos em aula que evidenciassem a análise das categorias elencadas.

Cabe ressaltar que, como a intervenção durou cerca de três meses, para podermos discutir mais detalhadamente as categorias propostas, optamos, no recorte aqui apresentado, por escolher uma tarefa para ser analisada. A tarefa 11 foi a escolhida porque fez parte da etapa final da intervenção, quando os alunos já tinham tido a possibilidade de refletir de maneira mais sistemática sobre seu processo inferencial. Além disso, esta nos pareceu uma tarefa pertinente para os objetivos do presente trabalho, já que nela é possível identificar todas as categorias propostas.

\section{Análise dos resultados}

Nesta seção, pretendemos discutir nossos resultados à luz do nosso referencial teórico. Nossa proposta vai ao encontro do que propõem Gabriel et al. (2016), ao dizerem que necessitamos de uma prática em sala de aula que considere o que a ciência já sabe sobre leitura, sobre a aprendizagem de leitura e que leve em conta o que um leitor considerado proficiente faz. Por isso, todas as tarefas propostas, inclusive a que será aqui analisada, levaram em conta tais aspectos. Como exemplo, há o fato de elaborarmos tarefas constantes de leitura (VARGAS, 2017), visto que sabíamos que poucas tarefas não poderiam fazer frente a, em muitos casos, anos de leitura como reprodução. Ainda, as tarefas mobilizam estratégias cognitivas e metacognitivas, já que muitos estudos mostram sua importância para a aprendizagem de leitura.

Antes de iniciarmos a análise propriamente dita, vamos contextualizar mais a tarefa. A tarefa analisada aqui é a de número 11, o que significa que os alunos já tinham uma caminhada com a aprendizagem de leitura proposta nesta pesquisa. Nesta tarefa, os alunos deveriam estabelecer relações com uma música já trabalhada em uma tarefa anterior - “Ai, que saudades da Amélia" - e com a música lida na tarefa 11 - "Desconstruindo Amélia", da cantora Pitty. Os alunos iniciaram estabelecendo hipóteses de relação entre as músicas citadas. Logo em seguida, os alunos leram uma biografia da cantora e conversaram sobre o objetivo da tarefa, que sempre vinha explícito em cada uma delas. Como apontam Kleiman (2001) e Duffy e Roehler (1989), 
é fundamental que o professor estabeleça objetivos de leitura, especialmente com alunos menos experientes, para que, com o tempo, possam estabelecer seus próprios objetivos.

Ao início da tarefa, é possível notar que há um trabalho com o estabelecimento de hipóteses, como aponta o excerto abaixo. A professora-pesquisadora questiona sobre a relação que pode haver entre as músicas, e esse estabelecimento de hipóteses se dá a partir do conhecimento prévio (GERHARDT et al., 2015) que os alunos têm sobre a "personagem" Amélia a partir do trabalho realizado em uma tarefa anterior (destaques nossos em negrito).

Professora-pesquisadora: Tá. A música que a gente vai trabalhar o nome dela é "Descontruindo Amélia”, e aí a gente viu uma música que falava sobre a Amélia né? Então, obviamente tem alguma relação. Eu queria que vocês pensassem que relação que vocês acham que tem, pensando nesse título.

Emily $^{6}$ : Processos e recursos ${ }^{7}$ ?

Professora-pesquisadora: Isso, processos e recursos 4. Tarefa 11.

Professora-pesquisadora: Tem que prestar atenção ali ao objetivo de leitura.

Alguém: Vai mudar.

Professora-pesquisadora: Mudar a música, tá, mas em que sentido?

Natália: O pensamento machista que tem na Amélia.

Professora-pesquisadora: $\mathrm{O}$ que que tu acha que tem de machista na Amélia?

Natália: (inin) Ela era mulher de verdade.

Professora-pesquisadora: Aham. Então, que será que a Pitty faz em "Desconstruindo Amélia"?

O que vocês acham que vai ter nessa música?

Silvia: Coisa boa, né?

Professora-pesquisadora: Que expectativa, olha que às vezes, né, a gente se decepciona

Alguém: Qual é pra entrar?

Professora-pesquisadora: Processos e recursos 4, tarefa 11.

Alguém: Eu acho que ela vai apoiar.

Professora-pesquisadora: Acha que ela vai apoiar o quê? A Amélia? Ou apoiar?

Mesma aluna: Nem sei.

Professora-pesquisadora: Não, fala. O que a gente tá fazendo...

Mesma aluna: Não, é que a senhora pegou e falou isso nem sempre...

\footnotetext{
${ }^{6}$ A fim de manter o sigilo quanto à identidade dos participantes, foram adotados pseudônimos.

${ }^{7}$ Aqui, a aluna faz referência a partes em que estavam estruturadas as tarefas da WebQuest.
} 
Professora-pesquisadora: Não, mas eu tô só fazendo o advogado do diabo, não vai achar... Eu tô aqui pra botar umas pilha. Não quer dizer que vai ser assim, não tô dizendo que ela vai se decepcionar.

No mesmo excerto, é possível perceber que a professora-pesquisadora enfatiza a importância do objetivo de leitura, ao chamar a atenção dos alunos para que atentem ao objetivo proposto na tarefa (“estabelecer relações entre duas músicas”). A professora-pesquisadora se preocupa em, além de desenvolver e trazer o objetivo claro na tarefa, manter este objetivo (GERHARDT et al., 2015), destacando-o ao longo do desenvolvimento da tarefa.

No momento seguinte da aula, a professora-pesquisadora fala sobre o estabelecimento de hipóteses de forma explícita, como evidencia o excerto abaixo.

Professora-pesquisadora: A ideia é vocês pensarem em hipóteses de leitura, porque é uma coisa bem importante quando a gente lê, a gente faz isso naturalmente. Mas a partir do título, eu quero que vocês imaginem. Ah, eu acho que a música fala sobre isso e aí pensando na relação que tem com a Amélia. Que vocês acham, gurias, vocês aqui da frente, (inin) Gisele. Uma música que fala descontruindo Amélia, vai falar sobre o quê?

A fala da professora-pesquisadora parece ter um efeito positivo, já que outros alunos participam com suas hipóteses a partir do que foi dito pela professora-pesquisadora, como mostra o excerto na sequência. Por isso, reforçamos a ideia de que o aluno precisa refletir explicitamente sobre seu processo inferencial, para que perceba processos relacionados à leitura que já aplica, mas que, ao serem trazidos à tona, podem ser aplicados com ainda mais eficiência.

Professora-pesquisadora: A gente ouviu a música que fala da Amélia né? Então, o que vocês acham que pode dizer essa?

Gisele: Totalmente o contrário da música.

Professora-pesquisadora: Tá, mas o que é o contrário?

Cristiano: Ela não fazer o que ele quer.

Professora-pesquisadora: Ela não fazendo o que ele quer...

Aline: Eu acho que...

Professora-pesquisadora: Tá, pode ser, ela não fazendo o que ele quer, mais alguma hipótese, alguém acha, vocês o que vocês acham?

Maria: Vai descontruir aquele conceito que ele criou sobre a Amélia. 
Professora-pesquisadora: Vai trazer outras mulheres talvez.

Maria: Um conceito diferente.

Professora-pesquisadora: Um conceito diferente de mulher, tá, porque ele fala, Amélia que era mulher de verdade, então vai trazer um conceito diferente sobre mulher, tá.

Natália: Eu acho que ela vai seguir a mesma coisa.

Professora-pesquisadora: Vai seguir a mesma coisa?

Aline: Eu quero fazer uma pergunta. Esse coisa aqui "e eis que de repente ela resolve então mudar" ${ }^{8}$ tem a ver com a música?

Professora-pesquisadora: Tem, sempre as tarefas, os títulos têm a ver com a música.

Aline: Tá. Então eu acho que ela vai ser que nem a Amélia e vai dá um troço na cabeça dela e ela resolver mudar.

Professora-pesquisadora: Ó, uma hipo... outra hipótese.

Natália: Ó, essa é boa.

Neste excerto, destacamos que uma das alunas consegue estabelecer sua hipótese a partir de seu conhecimento prévio sobre a própria estruturação da WebQuest, encontrando uma pista na tarefa que justificasse a hipótese que fez sobre a música.

Em seguida, os alunos leram uma biografia da cantora Pitty, já que ela é a compositora e cantora da música trabalhada na tarefa. O objetivo era ampliar o conhecimento prévio dos alunos sobre a cantora para que pudessem estabelecer possíveis relações entre a música e o que descobriram ou já sabiam sobre a cantora. Nenhum aluno chegou a estabelecer essa relação, mas, ainda assim, o objetivo de ampliar o conhecimento prévio pode ser considerado atingido, uma vez que entendemos que essa nova leitura tenha contribuído para a construção de novos sentidos para a canção lida anteriormente, já que novas informações foram introduzidas sobre a cantora/compositora da canção, ainda que esses novos sentidos não tenham sido explicitados. Abaixo, está o excerto em que a professora-pesquisadora propõe a leitura da biografia mencionada e explicita o objetivo de tal leitura.

Professora-pesquisadora: Tá, que que vocês vão fazer agora. Vocês vão ali no recurso "a", que é a biografia da Pitty, só pra vocês conhecerem um pouquinho mais da Pitty e pensarem depois se o que vocês viram sobre a Pitty pode ter alguma relação com o que ela canta e com essa

\footnotetext{
${ }^{8}$ Aqui, a aluna faz menção ao título da tarefa.
} 
música especificamente, tá? É recurso "a" ali, a biografia da Pitty. É bem curtinha, bem simplesinha.

Na continuidade, um aluno pergunta sobre o objetivo de leitura da tarefa, ajudando assim a professora-pesquisadora a fazer a manutenção do objetivo da tarefa especificamente e da WebQuest como um todo para a turma.

Cristiano: (inin) relação com a música (inin)

Professora-pesquisadora: Tá, então esse é o objetivo. Então vocês têm que pensar lá na música “Ai, que saudades da Amélia', pensar nessa e ver que relação que tem e claro não perdendo nosso tema que é a representação da mulher. Então as duas vão falar sobre mulher.

A tarefa foi organizada para que os alunos ouvissem um trecho da música e pudessem verificar as hipóteses que haviam estabelecido a partir do título da música, como deixa claro o excerto a seguir.

Professora-pesquisadora: Antes da gente continuar, eu queria que vocês pensassem então nas hipóteses que apareceram aqui e se vocês acham que até esse momento têm a ver com o que vocês pensaram ou não. Alguns falaram "vai ser uma mulher diferente", acho que foi tu que falou, "vai ser outra mulher". Alguém falou que ela ia ter um troço e ia mudar, e o Cristiano, que que o Cristiano falou? Já não lembro.

Cristiano: Que ia ser diferente do que ele queria que a mulher fosse.

Professora-pesquisadora: Tá, que ela não ia fazer nada do que ele queria, né, era isso. Até aqui, vocês acham que as hipóteses... Tu acha que a tua continua?

Aline: Sim

Professora-pesquisadora: Tu acha que a tua continua. Cristiano acha também?

Cristiano: É (inin)

Professora-pesquisadora: E a Manuela acha que continua com essa hipótese de leitura até aqui ou não?

Maria: Acho que sim.

Professora-pesquisadora: Como vocês acham que essa música vai continuar?

Alguém: Ela vai ter um troço. 
Professora-pesquisadora: Ela vai ter um troço (risos). Todo mundo acha que ela vai ter um troço ou tem alguém que acha que ela não vai ter um troço? Melhor definição, ela vai ter um troço. Todo mundo concorda que ela vai ter um troço?

Cristiano: Vai.

Professora-pesquisadora: Vamos ver se ela vai ter um troço (risos).

Neste excerto, a professora-pesquisadora propõe a verificação das hipóteses. A maioria dos alunos parece não flexibilizar suas hipóteses, pois ainda acredita no distanciamento em relação às características de Amélia que apareciam em “Ai, que saudades da Amélia”. Mas, como no trecho do videoclipe visto, até então, não havia nenhum indicativo deste distanciamento, todos parecem concordar que a hipótese mais próxima do que acontece é a da aluna Aline, já que, nas suas palavras, a Amélia da música sob análise "vai ter um troço", o que significa que há aproximações no início da música e que, em um determinado momento, haverá um rompimento, uma mudança que gera o distanciamento apontando por todos, provavelmente ligado ao uso da palavra "desconstruindo" e também, como a aluna Aline indicou anteriormente, ao que o título da tarefa sugere: "E eis que de repente ela resolve então mudar".

Mesmo a música indicando, até aquele momento, que ela não mostrava uma Amélia diferente da anterior, aparentemente contrariando a hipótese inicialmente levantada, os alunos, em um primeiro momento, não flexibilizam suas hipóteses, o que pode estar ligado a uma falha de automonitoramento, uma vez que eles não conseguiram perceber que as hipóteses não se sustentavam. Por outro lado, ao mesmo tempo, quando a hipótese da aluna Aline foi trazida à tona, todos pareceram concordar que essa era a mais adequada, o que pode indicar uma relação bem-sucedida entre levantamento de hipóteses e automonitoramento da leitura. E dentro desse quadro, o título da tarefa de leitura parece ter colaborado como orientadora do contexto mais amplo de interpretação.

Após toda a discussão sobre as hipóteses e depois de ouvirem a música inteira, os alunos responderam por escrito a algumas perguntas. As perguntas foram as seguintes: "como a imagem da cantora auxilia na desconstrução da Amélia?”; “a biografia da Pitty também contribui para a desconstrução ou não?”; e “como o clipe ajuda a desconstruir Amélia?”.

Em todas as tarefas da WebQuest, os alunos deveriam avaliar se as perguntas feitas eram inferenciais ou literais. Assim, acreditamos que os alunos poderiam saber o que era esperado da pergunta, se deveriam simplesmente selecionar do texto, se aproximando da reprodução, ou fazer inferências, relacionando seus conhecimentos prévios com os selecionados no texto, o que contribui para a avaliação e o monitoramento da compreensão. O excerto abaixo ilustra o momento descrito acima. 
Professora-pesquisadora: E as perguntas, vocês acham que é inferencial ou é literal?

Cristiano: Eu acho que é inferencial.

Professora-pesquisadora: Todas?

Alguém não identificado: É (sussurrando).

Professora-pesquisadora: Por que vocês acham que é inferencial?

(silêncio)

Quando a professora-pesquisadora pede que os alunos justifiquem por que consideram as perguntas feitas como inferenciais, os alunos se mantêm alguns segundos em silêncio, até que uma aluna resolve falar, como mostra o excerto na sequência. Este silêncio talvez indique a dificuldade em não reproduzir, já que não há uma resposta pronta. Também pode indicar a dificuldade que os alunos têm de lidar com o erro, não o entendendo como parte do processo de aprendizagem.

Natália: Porque a gente tem que fazer uma comparação com a música original.

Professora-pesquisadora: Aí vocês têm que buscar no conhecimento prévio de vocês, né, o que vocês sabem sobre a Amélia, vocês têm que buscar também o que vocês sabem, já sabiam ou ouviram na biografia sobre a Pitty, né, então todas são inferenciais. Podem responder agora.

Após a fala da aluna, a professora-pesquisadora enfatiza a importância do conhecimento prévio na construção de inferências. $\mathrm{Na}$ aula seguinte, as perguntas foram retomadas e discutidas pelo grupo, como vemos no excerto a seguir.

Professora-pesquisadora: Gisele, lê então, por favor.

Gisele: (lendo) Como a imagem da cantora auxilia na desconstrução da Amélia? A biografia da Pitty também contribui para a desconstrução ou não? Justifique.

Professora-pesquisadora: O que que tu colocou?

Gisele: Ah, esqueci.

Professora-pesquisadora: É só ler.

Gisele: Acho que não .

Professora-pesquisadora: Tá, e tu justificou como?

Gisele: (Inin)

Professora-pesquisadora: Como que a imagem da Pitty ajuda? Tu acha que ajuda?

Gisele: Não. 
O que chama a atenção neste excerto é a resistência da aluna em falar e, quando solicitada, em justificar suas impressões. Sua fala é tão baixa que não é possível identificar o que diz. Isto nos faz pensar em como a escola parece ser o lugar para o professor falar e para o aluno reproduzir, e em como os alunos, em geral, não se sentem confortáveis quando essa lógica muda, sendo essa mudança uma importante contribuição a ser trazida pelos estudos em metacognição para as práticas escolares.

Em seguida, outra aluna se manifesta, conseguindo explicar o porquê de suas impressões.

Professora-pesquisadora: Tu acha que a imagem da Pitty não ajuda na desconstrução da Amélia? Tem alguém que acha que a imagem ajuda? Todo mundo acha que não? O que vocês acham? Eduarda?

Aline: Acho que sim.

Professora-pesquisadora: Ah, tá, obrigada. Por que vocês acham isso?

Aline: Eu botei por causa que ela tá bem vaidosa e na Amélia dizia que ela não tinha nenhuma vaidade e a Pitty é bem vaidosa, se maquiando, se arrumando, arrumando o cabelo.

Professora-pesquisadora: Então a Aline consegue justificar a leitura dela, ela diz "eu acho que ajuda na desconstrução porque ela é vaidosa, tá maquiada (inin) a Amélia não tinha nenhuma vaidade". Então, ó, é uma leitura que faz sentido. Ela consegue justificar. Tu consegue justificar por que tua acha que não?

Gisele: Não.

Neste excerto, a aluna Aline, a partir de elementos do clipe, define Pitty como uma mulher vaidosa, associando isso explicitamente à maquiagem e ao cabelo. Ainda neste excerto, a professora-pesquisadora tenta fazer com que os alunos percebam que não existe uma única leitura possível, mas que precisam encontrar pistas que justifiquem suas leituras, o que parece ter sido a maior dificuldade dos alunos.

Na próxima pergunta discutida (“como o clipe ajuda a desconstruir Amélia?”), é interessante perceber como, nas respostas, os alunos apresentam uma retomada da hipótese levantada pela aluna Aline debatida a partir do título da música. A aluna falou sobre Amélia sofrer uma mudança, hipótese que é retomada nas respostas abaixo, o que evidencia um processo de automonitoramento da leitura.

Professora-pesquisadora: Tá, e alguém colocou alguma coisa diferente? 
Michele: Eu botei que ajuda. No momento que ela resolve então mudar, Amélia não deixou de ser mulher de verdade, não deixou de fazer o que ela fazia (inin) mais valorizada e sem deixar de ser mulher.

Professora-pesquisadora: Cristiano, o que tu botou?

Cristiano: Botei que no início do clipe a cantora é como a Amélia, cuidava dos filhos dela. (...) resolveu se dar valor e depois foi pra festa. Foi isso que eu coloquei.

Emily: Eu botei que ela muda completamente por causa que antes ela era de um jeito e agora ela tava de outro.

Em seguida, a professora-pesquisadora fala um pouco sobre a sua leitura, discutindo seu processo inferencial, que parece ser diferente da maioria dos alunos neste aspecto específico em análise na tarefa.

Professora-pesquisadora: Vocês acham que o clipe consegue mostrar isso que ela muda completamente? O que vocês acham? Acham que sim? Mostra mais parecida com a Amélia e num determinado momento mudando?

Alguém: Sim.

Professora-pesquisadora: Todo mundo acha que sim? Não sei se eu concordo, mas tudo bem. Vocês podem achar, só tô dizendo que eu não sei se o clipe evidencia tudo, acho que pela letra a gente consegue pensar que sim, ela mudou, deu um troço nela, mas acho que o clipe não ajuda muito. O clipe já mostra a Pitty como a gente imagina a Pitty hoje, então acho que o clipe não ajuda tanto nesse sentido.

Ressaltamos essa fala, pois entendemos, como dito anteriormente, que este espaço para que o professor apresente suas leituras é também importante, justamente para que os alunos possam entender como é esse processo leitor mais amadurecido. Entretanto, é preciso que se tome cuidado, como o faz a professora-pesquisadora em sua fala, para que essa leitura seja colocada apenas como uma leitura possível. O foco, assim, está no processo de leitura construído pela professora-pesquisadora e não nos sentidos construídos por ela como os únicos possíveis.

\section{Considerações finais: desautomatizando o olhar para a leitura}

Como foi apontado na introdução, as pesquisas sobre leitura não parecem mudar o seu ensino na escola. Sem desconsiderar toda a realidade que envolve o trabalho do professor no 
Brasil, aqui apresentamos um caminho para essa mudança: o trabalho com a metainferência, que se dá por meio da reflexão sobre o processo inferencial, com o auxílio do professor no desenvolvimento de estratégias de leitura cognitivas e metacognitivas (KLEIMAN, 2001). A principal contribuição desta pesquisa se dá na medida em que mostra que é possível ensinar leitura, pela mediação do processo, e que não podemos esperar que nossos alunos se tornem leitores proficientes e críticos somente lendo, por tentativas e erros. Nossa análise evidencia a mobilização das estratégias de leitura aprendidas, para além da reprodução das habilidades automatizadas (DUFFY E ROEHLER, 1989).

Além disso, o trabalho mostra uma didática para o ensino de leitura, que não é a única, mas é um caminho possível por meio da leitura integrativa (VARGAS, 2017), que entende e valoriza os inputs envolvidos nessa integração: conhecimento prévio e informação selecionada do texto. Além de valorizar os inputs, no recorte da intervenção aqui discutido, eles foram explicitados por meio da reflexão sobre o processo inferencial, trazendo à tona o que todo leitor já faz, mas sem uma reflexão consciente e sem a sua devida valorização. A falta da valorização do processo inferencial ocorre porque, em geral, ou o aluno é incentivado a trazer a resposta única do livro didático, que é considerada a correta pelos professores, ou responde o que construiu, mas não tem sua resposta valorizada (GERALDI, 2013).

É evidente que uma intervenção de cerca de três meses não resolveria os problemas pelos quais os alunos passam durante toda a educação básica, posto que, como apontado na introdução, o trabalho com as estratégias de leitura precisa ser longitudinal. Não era essa a pretensão da pesquisa, mas sim apontar uma direção para um trabalho contínuo e sistemático com o ensino de leitura. Trabalho esse que deve mobilizar explicitamente os processos que estão envolvidos no ato de ler e, assim, fazer com que os alunos tragam à tona conhecimentos que, como eles mesmos apontaram, normalmente não são discutidos ou pensados em aula e que podem influir em como pensam sobre a leitura e, consequentemente, em como leem.

\section{Referências}

AZAMBUJA, Flávia. Metainferência: Uma proposta para a leitura de textos multimodais na escola. Dissertação (Mestrado em Ensino de Línguas) - Universidade Federal do Pampa Unipampa, Bagé, 2018. Mestrado em Ensino de Línguas da Universidade Federal do Pampa Unipampa. $156 \mathrm{p}$.

BATISTA, A. A. G. (2003). A avaliação dos livros didáticos: para entender o Programa Nacional do Livro Didático (PNLD). In: Rojo, R.; Batista, A. A. G. (orgs.). Livro didático de língua portuguesa, letramento e cultura de escrita. Campinas: Mercado de Letras, p. 25-67. 
BATISTA, A. A. G. (2004). O Processo de escolha de livros e seus condicionantes: um estudo exploratório. In: Batista, A. A. G.; Costa Val, M. G. (orgs.). Livros de Alfabetização e de Português: os professores e suas escolhas. Belo Horizonte: Ceale; Autêntica, p. 29-74.

BATISTA, A. A. G. (2009). O conceito de "livros didáticos". In: Batista, A. A. G.; Galvão, A. M. O. (orgs.). Livros escolares de leitura no Brasil - elementos para uma história. Campinas: Mercado de Letras, p. 41-73.

BATISTA, A. A. G.; COSTA VAL, M. G. (2004). Livros Didáticos, controle do currículo, professores: uma introdução. In: Batista, A. A. G.; Costa Val, M. G. (orgs.). Livros de Alfabetização e de Português: os professores e suas escolhas. Belo Horizonte: Ceale; Autêntica, p. 9-28.

BOTELHO, P. F.; NEVES, F. E. (2019). Perspectivas metacognitivas e metalinguísticas para o ensino de leitura e escrita em língua materna. Revista do GELNE, v. 21, n. 2, p. 189-201.

CAVALCANTE, V. M. P. (2015). Contribuições do ensino de estratégias metacognitivas de leitura no ensino fundamental. Dissertação de Mestrado em Letras. Universidade Estadual de Montes Claros, Montes Claros.

DÍAZ, M. G. de. (2003). La metainferencia en la lectura en inglés como lengua extranjera. In: IV Simposio internacional la lectura y la escritura: investigación y didáctica, Anais... Mérida, SILE, p.1-9.

DUFFY, G. G.; ROEHLER, L. R. (1989). Why strategy instruction is so difficult and what we need to do about it. In: Mccormick, C. B.; Miller, G.; Pressley, M. (eds.). Cognitive Strategy Research: from basic research to educational applications. Springer-Verlag New York Inc., New York, p.133-156.

DUQUE, P. H. (2015). Discurso e cognição: uma abordagem baseada em frames. Revista da Anpoll, v. 39, n. 1, p. 25-48.

FAUCONNIER, G.; TURNER, M. (2002). The way we think: conceptual blending and the mind's hidden complexities. Nova York: Perseus Books Group.

GABRIEL, R.; KOLINSKY, R.; MORAIS, J. (2016). O milagre da leitura: de sinais escritos a imagens imortais. D.E.L.T.A. v. 32, n. 4, p. 919-951.

GERALDI, J. W (1991). Portos de passagem. São Paulo: WMF Martins Fontes, 2013.

GERHARDT, A. F. L. M. (2010). Integração conceptual, formação de conceitos e aprendizado. Revista Brasileira de Educação. v. 15, n. 44, p. 247-263.

GERHARDT, A. F. L. M.; BOTELHO, P. F.; AMANTES, A. M. (2015). Metacognição, objetivos de leitura e atividades didáticas de língua portuguesa. Revista Brasileira de Linguística Aplicada. v. 15, n. 1, p. 1-30.

KLEIMAN, A. (1993). Oficina de leitura: teoria e prática. Campinas: Pontes, 2001. 
KLEIMAN, A. (1989). Texto e leitor: aspectos cognitivos da leitura. Campinas: Pontes, 2009.

KLEIMAN, A. B.; MORAES, S. E (1999). Leitura e interdisciplinaridade: tecendo redes nos projetos da escola. Campinas: Mercado de Letras.

LAJOLO, M. (1993). Do mundo da leitura para a leitura do mundo. São Paulo: Ática, 2008.

MARCUSCHI, L. A. (2003). Compreensão do texto: algumas reflexões. In: Dionísio, A. P.; Bezerra, M. A. (orgs.). O livro didático de português: múltiplos olhares. Rio de Janeiro: Lucerna, p. 48-61.

ROJO, R. (2003). O perfil do livro didático de língua portuguesa para o ensino fundamental ( $5^{\mathrm{a}}$ a $8^{a}$ séries). In: Rojo, R.; Batista, A. A. G (orgs.). Livro didático de língua portuguesa, letramento e cultura da escrita. São Paulo: Mercado de Letras, p. 69-99.

ROJO, R.; MOURA, E. (Orgs.) (2012). Multiletramentos na escola. São Paulo: Parábola.

TRIPP, D. (2005). Pesquisa-ação: uma introdução metodológica. Educação e Pesquisa. v. 31, n. 3 , p. 443-466.

VARGAS, Diego da Silva. O plano inferencial em atividades de leitura: livro didático, cognição e ensino. Fevereiro 2012. Dissertação (Mestrado em Letras) - Universidade Federal do Rio de Janeiro. Rio de Janeiro, 2012. Programa em Pós-Graduação em Letras (Letras Vernáculas) da Universidade Federal do Rio de Janeiro - UFRJ.

VARGAS, Diego da Silva. Por uma visão cognitivista do processo de inferenciação em leitura. Revista Ciência e Cognição, v. 20, p. 313-330, 2015. Disponível em: http://www.cienciasecognicao.org/revista/index.php/cec/article/view/1024/pdf_64. Acesso em: 07 out. 2017

VARGAS, Diego da Silva. O plano inferencial de leitura e o ensino de espanhol na escola brasileira: cognição distribuída, políticas cognitivas e livro didático. Junho 2017. Tese (Doutorado em Letras) - Universidade Federal do Rio de Janeiro. Rio de Janeiro, 2017. Programa de Pós-graduação em Letras Neolatinas da Universidade Federal do Rio de Janeiro UFRJ. 396 p. Disponível em: http://www.letras.ufrj.br/pgneolatinas/site/wpcontent/uploads/2017/08/TESE-FINAL-REVISADA.pdf Acesso em: 10. jan. 2017. 